Proceedings

\title{
Work-Hardening Behavior of Cold Rolled EUROFER97 Steel for Nuclear Fusion Applications ${ }^{\dagger}$
}

\author{
Giulia Stornelli 1,* Andrea Di Schino ${ }^{2}$, Roberto Montanari ${ }^{1}$, Claudio Testani ${ }^{3}$, Alessandra Varone ${ }^{1}$ and Silvia \\ Mancini 4
}

Citation: Stornelli, G.; Di Schino, A.; Montanari, R.; Testani, C.; Varone, A.; Mancini S. Title. Mater. Proc. 2021, 3, x.

https://doi.org/10.3390/xxxxx

Published: 22 February 2021

Publisher's Note: MDPI stays neutral with regard to jurisdictional claims in published maps and institutional affiliations.

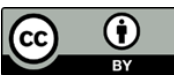

Copyright: $\odot 2021$ by the authors. Submitted for possible open access publication under the terms and conditions of the Creative Commons Attribution (CC BY) license (http://creativecommons.org/licenses/by/4.0/).
1 Dipartimento di Ingegneria Industriale, Università di Roma “Tor Vergata”, Via del Politecnico 1, 00133 Roma, Italy; giulia.stornelli@students.uniroma2.eu (G.S.), roberto.montanari@uniroma2.it (R.M.), alessandra.varone@uniroma2.it (A.V.)

2 Dipartimento di Ingegneria, Università di Perugia, Via G. Duranti 93, 06125 Perugia, Italy; andrea.dischino@unipg.it (A.D.S.)

3 CALEF-ENEA CR-Casaccia, Via Anguillarese 301, 00123 S. Maria di Galeria, Rome, Italy; claudio.testani@consorziocalef.it (C.T.)

4 RINA Consulting Centro Sviluppo Materiali, Via di Castel Romano 100, 00128 Roma, Italy; silvia.mancini@rina.org (S.M.)

* Correspondence: giulia.stornelli@students.uniroma2.eu

+ Presented at the title, place, and date.

\begin{abstract}
The reduced activation martensitic steel EUROFER97 is recognized in Europe as the reference steel for structural applications in future nuclear fusion reactors.

Usually, EUROFER97 steel plates are manufactured by hot rolling and successive heat treatments: (1) austenitization at $980^{\circ} \mathrm{C}$ for 30 minutes, (2) air cooling and (3) tempering at $760^{\circ} \mathrm{C}$ for 90 minutes. Recently, thermo-mechanical treatments have been investigated by us with the scope to improve the mechanical properties, namely to strengthen the steel without reducing its ductility. The experiments involve cold rolling with three reduction rates $(30 \%, 40 \%, 50 \%)$ and, for each of them, heat treatments at different temperatures in the range from $550{ }^{\circ} \mathrm{C}$ to $750{ }^{\circ} \mathrm{C}$. The mechanical and microstructural characterization of the samples after successive stages of the process is now underway and present work reports some preliminary results.

The characteristics of the samples after cold rolling have been examined by means of hardness tests, metallography and X-ray diffraction measurements and work-hardening is discussed in terms of dislocation density.
\end{abstract}

Keywords: Eurofer97; thermomechanical treatment; dislocation density

\section{Introduction}

Reduced-activation ferritic-martensitic (RAFM) steels, variants of conventional ferritic-martensitic steels, were developed to be used as structural materials in future nuclear fusion reactors and generation IV nuclear fission reactors [1,2].

EUROFER97 is the reference RAFM steel in Europe [1] for the test blanket module in ITER reactor [3] and for structural sections subjected to high radiation energy in DEMO: first wall, divertor, blanket, vessel [4-7].

The chemical composition of EUROFER97 steel was suitably modified to simplify the storage of radioactive waste after the disassembly of the reactor [8]. Some alloying elements, commonly present in Cr-Mo steels, were replaced with equivalent elements having a faster induced radiation decay [9]. The Mo was replaced with $\mathrm{W}$ and the $\mathrm{Nb}$ with $\mathrm{Ta}$ e $\mathrm{V}$. Furthermore, other elements such as $\mathrm{Ni}, \mathrm{Nb}, \mathrm{Mo}, \mathrm{Cu}$ and $\mathrm{N}$ were kept as low as possible [10].

When steels undergo neutron radiation, cascades of atomic displacements are generated [11] and He is produced by transmutation reaction [12]. Lattice defects, produced by 
atomic displacement, lead to a variation of the microstructure and micro composition with consequent dimensional instability and degradation of the mechanical proprieties. EUROFER97 steel is traditionally produced by means of a hot rolling process and subsequent heat treatment $[5,13]$ : austenitizition at $980^{\circ} \mathrm{C}$ for 30 minutes, air cooling and tempering at $760^{\circ} \mathrm{C}$ for 90 minutes [4]. This allow to achieve a tempered martensitic microstructure. Henceforth this state of the steel will be referred to as "standard EUROFER97" in comparison with the variant states investigated during the activity.

Based on the irradiation experiment conducted so far, EUROFER97 has shown good performance in the temperature range from $350{ }^{\circ} \mathrm{C}$ to $550{ }^{\circ} \mathrm{C}[13,14]$. Several studies have been conducted aimed to enlarge the operating temperature range for this steel $[15,16]$. The upper limit at $550^{\circ} \mathrm{C}$ is imposed by swelling and irradiation creep. To date, a possible solution to raise the maximum operating temperature is through an oxide dispersion strengthen (ODS) variant of EUROFER97 steel.

EUROFER97-ODS was fabricated by mechanical alloying of yttrium oxide powders $\left(\mathrm{Y}_{2} \mathrm{O}_{3}\right.$ at $\left.0.3 \mathrm{wt} . \%\right)[1,14,16]$. The presence of fine grain size and nanometric scale oxide particle [17] leads to an increase in mechanical performance at temperatures above $550^{\circ} \mathrm{C}$ [18]. Instead, regarding lower temperature limit, this depends on the loss of ductility. The lattice defects produced by neutron radiation, at temperature below to $350^{\circ} \mathrm{C}$, lead to an increase of Ductile-Brittle Temperature Transition (DBTT) [14]. Therefore, lowering the DBTT before irradiation would allow to lower the minimum operating temperature. It is well know that the only process that decreases the DBTT is the refinement of the grain size [19-21]. Moreover, a refinement of the microstructure would show many advantages in the nuclear application [14]. In literature was shown that a particularly fine microstructure, on micro and nanometric scale, obtained by hot or cold mechanical process followed by annealing, gives high mechanical strength (the grain boundaries limit the dislocation movement) and give high resistance to radiation $[4,19]$. The greater surface of grain boundaries guarantees more recombination centers of point defects [2] and lower susceptibility to He $[2,22]$. In literature, various strategy have been studied for the grain size strength on EUROFER97 steel, both during austenitization phase (reduction of prior austenitic grain) [22], and in the tempering phase [13]. About that, in this paper the effect of a thermo-mechanical process on the microstructure of EUROFER97 steel is reported, with the aim to improve the tensile properties and to evaluate the possible application in the fusion nuclear reactors. In particular, the work-hardening behavior was investigated after a cold rolling process and compared with traditional EUROFER97 steel. The characterization was carried out by means of hardness test, metallography and X-Ray diffraction measurements.

\section{Material and Methods}

The nominal steel chemical composition of EUROFER97 is reported in Table 1.

Table 1. Nominal steel chemical composition of EUROFER97 (wt.\%)(Fe to balance).

\begin{tabular}{cccccccc}
\hline $\mathbf{C r}$ & $\mathbf{C}$ & $\mathbf{M n}$ & $\mathbf{V}$ & $\mathbf{W}$ & $\mathbf{T a}$ & $\mathbf{T i}$ & $\mathbf{N}$ \\
\hline 8.93 & 0.12 & 0.47 & 0.2 & 1.07 & 0.14 & 0.009 & 0.018 \\
$\mathbf{P}$ & $\mathbf{S}$ & $\mathbf{B}$ & $\mathbf{S i}$ & $\mathbf{N b}$ & $\mathbf{M o}$ & $\mathbf{N i}$ & $\mathbf{C u}$ \\
\hline$<0.005$ & 0.004 & $<0.001$ & 0.006 & 0.002 & 0.0015 & 0.002 & 0.003 \\
\hline
\end{tabular}

The EUROFER97 steel in the standard condition, was subjected to cold rolling followed by recrystallization heat treatment. In particular, three different cold reduction (CR) ratios $(30 \%, 40 \%, 50 \%)$ were investigated.

In this work, the microstructure of standard EUROFER97 and after cold rolling process was analyzed and compared using a high-resolution electronic scanning microscope 
(FE-SEM Zeiss, Gemini Supra 25). Moreover, Vickers hardness (HV5) tests and X-Ray diffraction measurements were carried out to estimate of dislocation density.

Dislocation density $(\rho)$ was calculated from local micro-strain $(\varepsilon)$, using WilliamsonSmallman relation (1)[23].

The micro-strain $\varepsilon$ was estimated by full width at half maximum (FWHM) of the XRay diffraction peak [24].

$$
\rho=14.4 * \varepsilon^{2} * b^{-2},
$$

Where $b$ is the burger vector $(b \approx 0.25 \mathrm{~nm})$.

X-Ray diffraction spectra were obtained with Mo-K $\alpha$ radiation $(\lambda=0.703 \AA)$ and precision spectra were conducted, with angular steps of $2 \theta=0.005$ and counting time for step of $4 \mathrm{~s}$. For the estimation of $\varepsilon$, the $k \alpha 1$ component of the $\{100\}$ line of the spectrum was used.

\section{Results and Discussion}

The effect of cold plastic deformation on EUROFER97 microstructure is clearly visible in SEM images as shown in Figure 1. In particular, in Figure 1(a), prior austenite grains and laths decorated by carbides, as typical of tempered martensite, are clearly detectable. The effect of cold rolling on tempered martensite is reported in Figures $1(\mathbf{b})(\mathbf{c})(\mathbf{d})$. Such figures show a grain shape change: as a matter of fact, the grains become elongated, as the $\mathrm{CR}$ ratio increases.

The $k \alpha 1$ component of the $\{100\}$ line as obtained by $\mathrm{X}$-ray diffraction measurements is reported in Figure 2 for EUROFER97 in standard conditions and after cold rolling process. In Figure 2 all the reported peaks intensities are normalized. Results reported in Figure 2 show a diffraction peaks broadening following the $C R$ ratio increase. Such broadening is an index of the micro-strain increase (and thus the dislocation density). Based on such peaks broadening, dislocation density variation as a function of plastic deformation amount has been calculated according to equation 1 . Dislocation density and hardness values as a function of $C R$ are reported in Figure 3. Results show that an increase of CR from zero to $50 \%$ implies an increase of dislocation density from $7^{*} 10^{10}$ to about $3^{*} 10^{11} \mathrm{~cm}$ 2. Such increase appears to be quite powerful in terms of hardness variations, leading to a strong HV increase (from $200 \mathrm{HV}$ up to $280 \mathrm{HV}$ in the case of the $50 \%$ cold rolled material). Such effect appears to be very promising in terms of response to forthcoming heat treatment effect. In particular, preliminary results carried out on a cold rolled material showed the possibility to achieve very fine microstructures (about $200 \mathrm{~nm}$ grain size) after proper heat treatment [25]. 


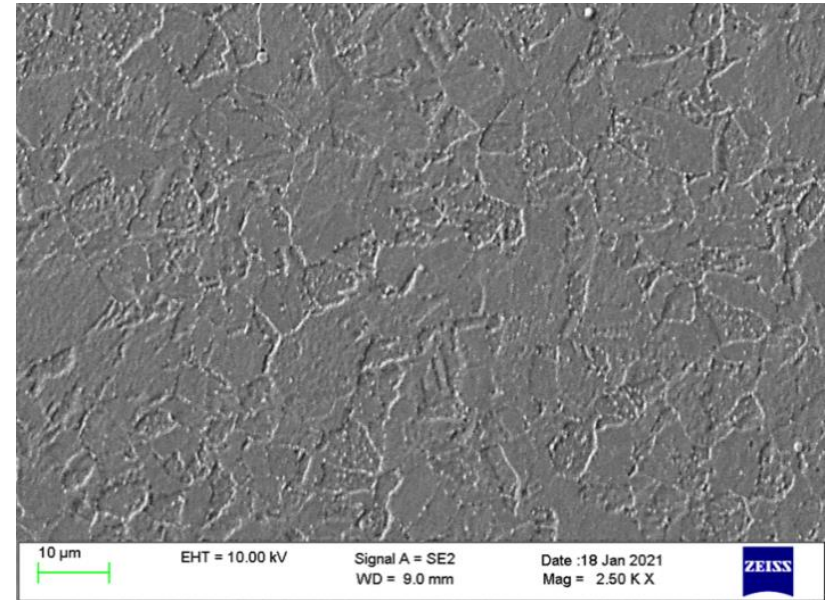

(a)

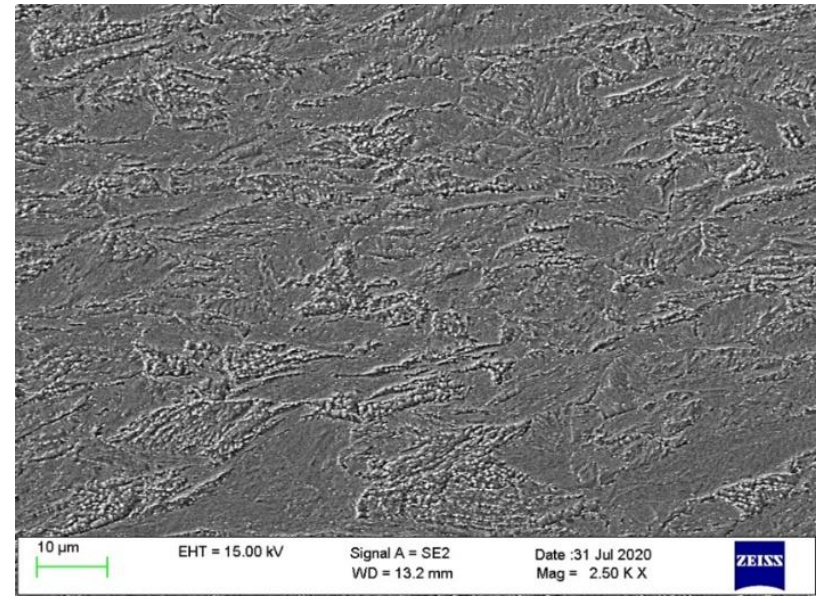

(c)

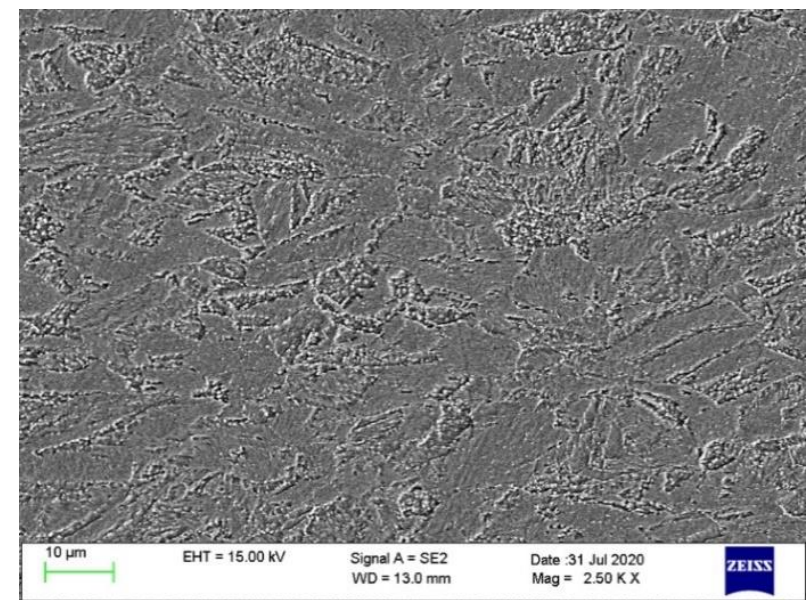

(b)

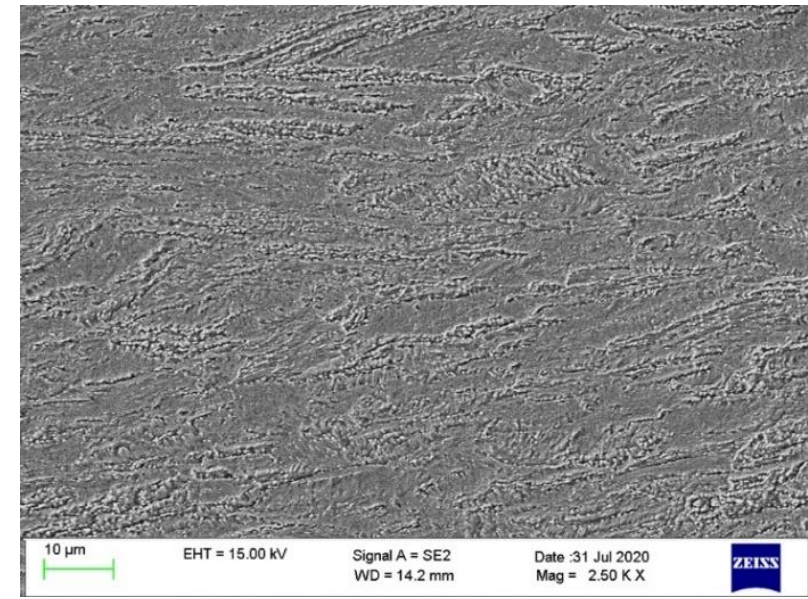

(d)

Figure 1. SEM images of (a) standard EUROFER97 state, (b) cold rolled EUROFER97 steel with CR: 30\%, (c) ) cold rolled EUROFER97 steel with CR: $40 \%$ and (d) ) cold rolled EUROFER97 steel with CR: 50\%.

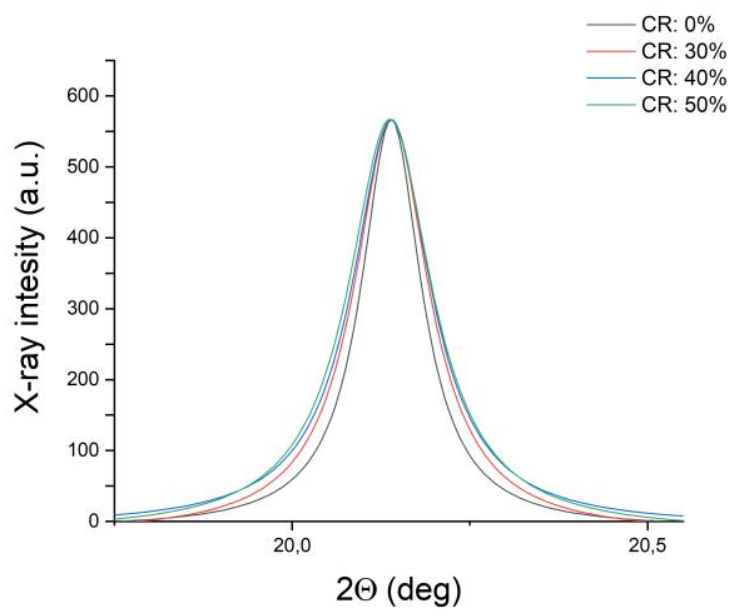

Figure 2. (a) Effect of the cold rolling process on the line shape of $\{100\}$ X-Ray diffraction peak, of EUROFER97 steel.

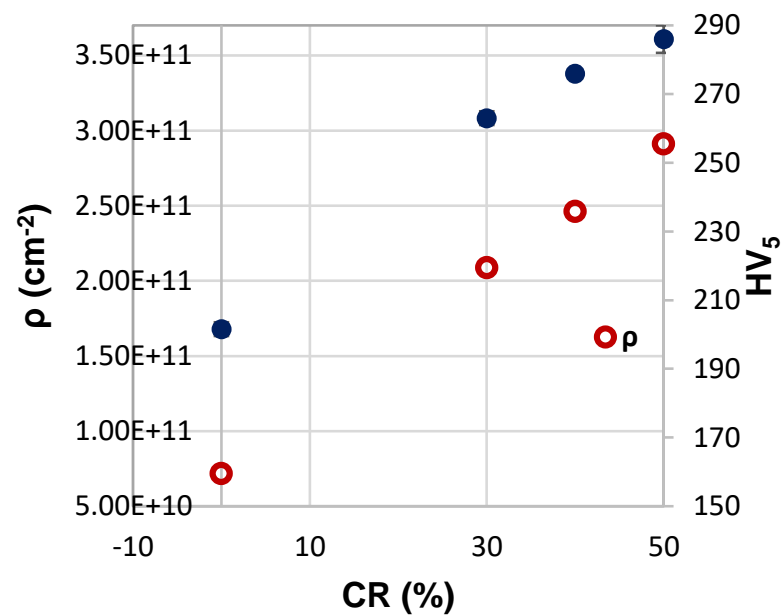

Figure 3. Effect of CR on Vickers hardness (HV5) and dislocation density calculated by Williamson-Smallman relaction (1) of EUROFER97 steel. 


\section{Conclusions}

In this paper the effect of cold rolling in terms of work-hardening on EUROFER97 steel is reported. Three different cold reduction ratios (CR) $(30 \%, 40 \%, 50 \%)$ were investigated and, for each ratio, microstructure analysis, Vickers hardness test and dislocation density measurement have been performed. The results obtained for cold rolled steel was compared to the EUROFER97 steel in the standard condition. Results show that the increase of CR from zero to $50 \%$ leads to an increase of dislocation density from $7^{*} 10^{10}$ to about $3^{*} 10^{11} \mathrm{~cm}^{-2}$. Such increase appears to be quite powerful in terms of hardness variations, there is a HV increase from $200 \mathrm{HV}$ for CR: $0 \%$, up to $280 \mathrm{HV}$ in the case of CR: $50 \%$.

These results are promising for fusion nuclear application and can be used as a starting point for more investigation, in order to understand the really effect of the complete thermo-mechanical process carried out, on the mechanical and irradiation performance of EUROFER97 steel.

\section{References}

Rieth, M.; Schirra, M.; Falkenstein, A.; Graf, P.; Heger, S.; Kempe, H.; Lindau, R.; Zimmermann, H. EUROFER 97, Tensile, charpy, creep and structural tests; 2003;

Zilnyk, K.D.; Oliveira, V.B.; Sandim, H.R.Z.; Möslang, A.; Raabe, D. Martensitic transformation in Eurofer-97 and ODS-Eurofer steels: A comparative study. J. Nucl. Mater. 2015, 462, 360-367, doi:10.1016/j.jnucmat.2014.12.112.

Tavassoli, A.A.F.; Alamo, A.; Bedel, L.; Forest, L.; Gentzbittel, J.M.; Rensman, J.W.; Diegele, E.; Lindau, R.; Schirra, M.; Schmitt, R.; et al. Materials design data for reduced activation martensitic steel type EUROFER. J. Nucl. Mater. 2004, 329-333, 257-262, doi:10.1016/j.jnucmat.2004.04.020.

Gaganidze, E.; Gillemot, F.; Szenthe, I.; Gorley, M.; Rieth, M.; Diegele, E. Development of EUROFER97 database and material property handbook. Fusion Eng. Des. 2018, 135, 9-14, doi:10.1016/j.fusengdes.2018.06.027.

Di Schino, A.; Testani, C.; Pilloni, L. Effect of thermo-mechanical parameters on the mechanical properties of Eurofer97 steel for nuclear applications. Open Eng. 2018, 8, 349-353, doi:10.1515/eng-2018-0040.

Chen, X.; Bhattacharya, A.; Sokolov, M.A.; Clowers, L.N.; Yamamoto, Y.; Graening, T.; Linton, K.D.; Katoh, Y.; Rieth, M. Mechanical properties and microstructure characterization of Eurofer97 steel variants in EUROfusion program. Fusion Eng. Des. 2019, 146, 2227-2232, doi:10.1016/j.fusengdes.2019.03.158.

Montanari, R.; Filacchioni, G.; Iacovone, B.; Plini, P.; Riccardi, B. High temperature indentation tests on fusion reactor candidate materials. J. Nucl. Mater. 2007, 367-370 A, 648-652, doi:10.1016/j.jnucmat.2007.03.099.

Fernández, P.; Lancha, A.M.; Lapeña, J.; Hernández-Mayoral, M. Metallurgical characterization of the reduced activation ferritic/martensitic steel Eurofer'97 on as-received condition. Fusion Eng. Des. 2001, 58-59, 787-792, doi:10.1016/S0920-3796(01)00563-4.

Tavassoli, A.A.F.; Diegele, E.; Lindau, R.; Luzginova, N.; Tanigawa, H. Current status and recent research achievements in ferritic/martensitic steels. J. Nucl. Mater. 2014, 455, 269-276, doi:10.1016/j.jnucmat.2014.06.017.

Mergia, K.; Boukos, N. Structural, thermal, electrical and magnetic properties of Eurofer 97 steel. J. Nucl. Mater. 2008, 373, 1-8, doi:10.1016/j.jnucmat.2007.03.267.

Cahn, R.W.; Haasen, P.; Kramer, E.J. Material science and technology, nuclear material, vol 10B.; 1994;

Weiß, O.J.; Gaganidze, E.; Aktaa, J. Quantitative characterization of microstructural defects in up to 32 dpa neutron irradiated EUROFER97. J. Nucl. Mater. 2012, 426, 52-58, doi:10.1016/j.jnucmat.2012.03.027.

Puype, A.; Malerba, L.; De Wispelaere, N.; Petrov, R.; Sietsma, J. Effect of processing on microstructural features and mechanical properties of a reduced activation ferritic/martensitic EUROFER steel grade. J. Nucl. Mater. 2017, 494, 1-9, doi:10.1016/j.jnucmat.2017.07.001.

Lindau, R.; Möslang, A.; Rieth, M.; Klimiankou, M.; Materna-Morris, E.; Alamo, A.; Tavassoli, A.A.F.; Cayron, C.; Lancha, A.M.; Fernandez, P.; et al. Present development status of EUROFER and ODS-EUROFER for application in blanket concepts. Fusion Eng. Des. 2005, 75-79, 989-996, doi:10.1016/j.fusengdes.2005.06.186.

Fu, J.; Brouwer, J.C.; Hendrikx, R.W.A.; Richardson, I.M.; Hermans, M.J.M. Microstructure characterisation and mechanical properties of ODS Eurofer steel subject to designed heat treatments. Mater. Sci. Eng. A 2020, 770, doi:10.1016/j.msea.2019.138568.

Testani C.; Di Nunzio, P.; Salvatori, I. Manufacturing of ODS RAFM Steel: Mechanical and Microstructural Characterization. MSF 2016, 879, 1639-44.

Fava, A.; Montanari, R.; Richetta, M.; Testani, C.; Varone, A. Analysis of Strengthening Mechanisms in Nano-ODS Steel Depending on Preparation Route. J. Mater. Sci. Eng. 2018, 07, doi:10.4172/2169-0022.1000474.

De Sanctis, M.; Fava, A.; Lovicu, G.; Montanari, R.; Richetta, M.; Testani, C.; Varone, A. Temperature dependent mechanical behaviour of ODS steels. Mater. Sci. Forum 2018, 941, 257-262.

Pickering, F.B.; Gladman, T. Metallurgical developments in carbon steels; 1963; Vol. ISI specia;

Di Schino, A.; Di Nunzio, P.E.; Turconi, G.L. Microstructure Evolution during Tempering of Martensite in a Medium-C Steel. Mater. Sci. Forum 2007, 558, 1435-1441.

Di Schino, A.; Alleva, L.; Guagnelli, M. Microstructure evolution during quenching and tempering of martensite in a medium C steel. Mater. Sci. Forum 2012, 715-716, 860-865. 
Pilloni, L.; Cristalli, C.; Tassa, O.; Salvatori, I.; Storai, S. Grain size reduction strategies on Eurofer. Nucl. Mater. Energy 2018, 17, 129136, doi:10.1016/j.nme.2018.06.023.

Williamson, G.K.; Smallman, R.E. Dislocation densities in some annealed and cold-worked metals from measurements on the X-ray debyescherrer spectrum. Philos. Mag. 1956, 1, 34-46.

Takebayashi, S.; Kunieda, T.; Yoshinaga, N.; Ushioda, K.; Ogata, S. Comparison of the dislocation density in martensitic steels evaluated by some X-ray diffraction methods. ISIJ Int. 2010, 50, 875-882.

Stornelli, G.; Montanari, R.; Testani, C.; Pilloni, L.; Napoli, G.; di Pietro, O.; di Schino, A. Microstructure Refinement Effect on EUROFER 97 Steel for Nuclear Fusion Application. Mater. Sci. Forum 2021, 1016, 1392-1397, doi:10.4028/www.scientific.net/msf.1016.1392. 